Document downloaded from:

http://hdl.handle.net/10251/148016

This paper must be cited as:

Albiol-Perez, S.; Gil-Gómez, J.; Muñoz-Tomás, M.; Gil Gómez, H.; Vial Escolano, R.; Lozano Quilis, JA. (2017). The Effect of Balance Training on Postural Control in Patients with Parkinson s Disease Using a Virtual Rehabilitation System. Methods of Information in Medicine. 56(2):138-144. https://doi.org/10.3414/ME16-02-0004

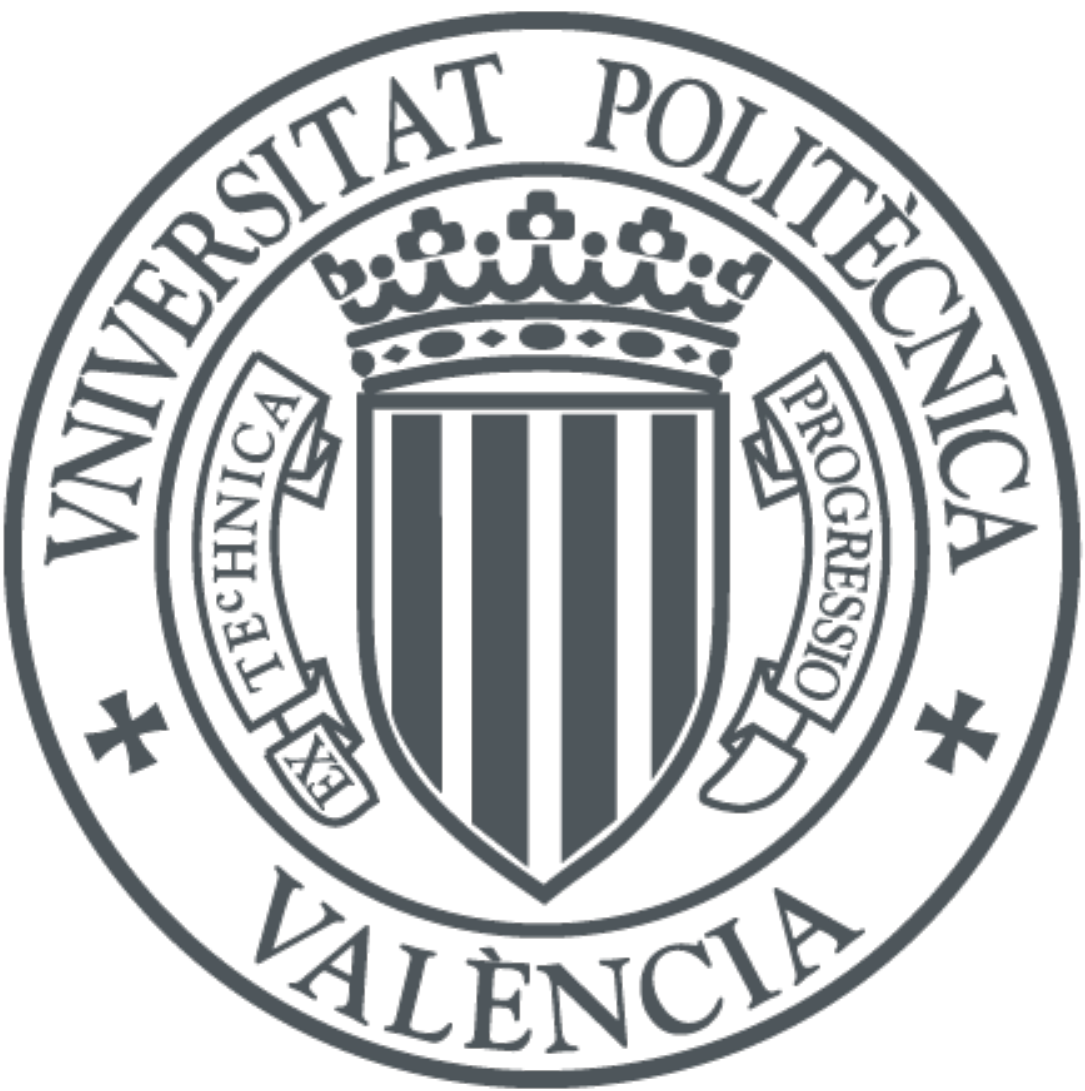

The final publication is available at

https://doi.org/10.3414/ME16-02-0004

Copyright Schattauer GmbH (Methods of Information in Medicine)

Additional Information 


\title{
The effect of balance training on postural control in patients with Parkinson's disease using a virtual rehabilitation system
}

\author{
S. Albiol-Pérez1', J.A. Gil-Gómez 2 , M.T. Muñoz-Tomás³ ${ }^{3}$ H. Gil-Gómez 2 , R. Vial-Escolano ${ }^{3}$, \\ J.A. Lozano-Quilis² \\ ${ }^{1}$ Aragón Health Research Institute (IIS Aragón), Universidad de Zaragoza, Teruel, Spain \\ ${ }^{2}$ Instituto Universitario de Automática e Informática Industrial, Universitat Politècnica de València, C. Vera S/N, \\ 46022, Valencia, SPAIN \\ ${ }^{3}$ Aragón Health Research Institute (IIS Aragón), Hospital S. José, Teruel, Spain
}

\begin{abstract}
Keywords
Parkinson's disease, spatial postural control, motor symptoms, Virtual motor rehabilitation, Virtual reality

Summary

Objectives: Parkinson's disease (PD) is a progressive neurodegenerative disorder characterized by motor clinical alterations among others. Postural problems have serious consequences for patients, not only limiting their daily life but also increasing some risks, like the risk of fall. Inadequate postural control and postural instability is a major problem in PD patients. A Virtual Motor Rehabilitation System (VMR) has been tested in patients with PD in the intervention period. Our purpose was to analyze the evolution of the spatial postural control during the intervention period, to see if there any changes caused precisely by this intervention.
\end{abstract}

Methods: Ten people with PD carried out 15 virtual rehabilitation sessions. We tested a groundbreaking system based on Virtual Motor Rehabilitation in two periods of time (baseline evaluation and final evaluation). In the training sessions, the participants performed a customizable treatment using a low-cost system, the Active Balance Rehabilitation system (ABAR). We stored the pressure performed by the participants every five hundredths of a second and we analyzed the patients' pressure when they maintained their body on the left, on the right, and in the center in sitting position. Our system was able to measure postural control in every patient in each of the virtual rehabilitation sessions.

\section{Results:}

There are no significant differences in the performance of postural control in any of the positions evaluated throughout the sessions. Moreover, the results show a trend to an improvement in all positions. This improvement is especially remarkable in the left/right positions, which are the most important positions in order to avoid problems such as the risk of fall. With regard to the suitability of the ABAR system, we have found outstanding results in enjoyment, success, clarity, and helpfulness.

Conclusions: Although PD is a progressive neurodegenerative disorder, the results demonstrate that patients with PD maintain or even improve their postural control in all positions. We think that the main factor influencing these results is that patients use more of their available cognitive processing to improve their postural control. The ABAR system allows us to make this assumption because the system requires the continuous attention of patients, promoting cognitive processing.

\section{Methods Inf Med}

\section{Introduction}

Parkinson's Disease (PD) is a chronic and a progressive neurodegenerative dysfunction which shows the loss of cells in the substantia nigra of the basal ganglia and produces alterations in the motor system [1]. The prevalence of $P D$ in developed countries is around $0.5-1 \%$ in people ranging from 65 to 69 years old, with a significant increase of $3 \%$ in people over 70 years old [2]. PD is known to be affected by age, gender, and geographical areas [3]. The incidence rate of $\mathrm{PD}$ in the world is approximately 8 to 18 per 100,000 person per year, with significant increases in people over 60 years old and a higher incidence in men compared to women [4]. In 2013, the incidence rate in the United States was over one million people diagnosed as having PD [5]. In Europe, in 2005, the incidence rates fluctuated from 108 to 257 per 100,000 and 11 to 19 per 100,000 per year [6]. In Asia (China and Taiwan), the incidence rates were between 1.5 and 8.7 per 100,000 people per year, with an increase of 94.5 per 100,000 and 100.2 per 100,000 in people ranging from 70 to 79 years old [7]. The estimated incidence for the year 2030 is 8.7 million people globally [8]. Due to these astonishing future incidence rates, it is necessary to develop novel techniques in the rehabilitation process.

Patients with PD suffer alterations which can be classified as non-motor [9] and motor clinical features [10]. Non-motor dysfunctions are: 1) neuropsychiatric symptoms [11]; 2) sleep disorders [12]; 3) fatigue [13]; 4) sensory symptoms [14]; 5) autonomic dysfunctions [15]; 6) gastrointestinal symptoms [16]; 7) cognitive impairments [17]; 8) affective symptoms [18]; and 9) lesser known symptoms such as visual burning or weight loss [19].

Motor symptoms are known by the acronym TRAP disorders: 1) tremors; 2) rigidity; 3) akinesia/bradykinesia; and 4) postural control. TRAP, combined with flexed posture and freezing of gait are the main dysfunctions in patients with PD [20].

The main disorder in patients with $P D$ is tremor, with a $70 \%$ of PD cases that suffer this alteration [21]. Tremor is a rhythmic back and forth movement that is shown in different parts 
of the body [22]. It is the most common symptom of $P D$, and, therefore, it is crucial to detect and analyze it. According to the Movement Disorder Society (MDS) consensus statement [23], tremor in PD is classified in three types. The First is rest tremor (RT), which is an oscillatory involuntary movement that is produced on the affected body segment when it is relaxed and supported by a surface [24]. The typical modal frequency of RT ranges from 4 to $6 \mathrm{~Hz}$ [25]. RT typically occurs in hands, legs, and different parts of the face such as the chin, lips, or jaw. The second type is postural tremor (PT), which is produced when a specific body part maintains a posture in a stable position against gravity [26].The third type is kinetic tremor (KT), which is a contraction of a muscle in relation to an action, such as holding a cup. The range of modal frequency is usually from 5 to $12 \mathrm{~Hz}$ [27].

Rigidity is defined by the improvements of resistance in different parts of the body in patients with $\mathrm{PD}$, with passive movements of the limbs (flexion/extension or rotation in a joint) that have been produced in neck, shoulders, hips, wrists, or ankles [9].

Akinesia/Bradykinesia is the slowness of a specific movement that is related to difficulties in thinking, starting an action, and producing an action. This fluctuation is shown with rapid and repetitive movements of the hand and reductions of amplitude and slowness of the heel [9].These symptoms are produced by muscle weakness, rigidity, tremor, movement variability, and slowing of thought [28]. In patients with $\mathrm{PD}$, this disturbance produces a significant impact on basic activities of daily living (ADL-dressing, eating, bathing etc.) and instrumented activities of daily living (IADLshopping, food preparation, housekeeping, laundry, etc.) [29].

Postural control is a motor skill that is determined by the sensorimotor system, which analyzes sensory information from visual, somatosensory, vestibular, and auditory systems. This ability produces the capacities to align the body and to stabilize the body's center of mass [30].

The Unified Parkinson's Disease Rating Scale (UPDRS) is the clinical scale that is most widely used by neurologists, researches, clinical specialist, etc. to assess non-motor experiences and motor experiences of daily living in PD [31, 32]. In the section three (Motor examination), UPDRS measures different aspects such as tremor at rest, posture, postural stability, etc. using a five-point Likert scale (from 0 "normal" to 5 "severe"). Unfortunately, since this test has inter-subject rating variability inconsistencies [33] and the symptoms of patients with PD change throughout the day, this test quantifies the result only at specific instant of time. Therefore, we propose to quantify spatial postural control by using low-cost technological systems.

\subsection{Related Work}

Traditional rehabilitation techniques include: 1) resistance training sessions of quadriceps muscle size, muscle force, and mobility [34, 35]; 2) motor training sessions based on gait patterns and dynamic range of distances [36]; 3) auditory cues related to balance rehabilitation using bobath, relaxation, or stretching [37].

Virtual Motor Rehabilitation (VMR) is composed of a group of novel and customized systems that focus on rehabilitation sessions in patients with $\mathrm{PD}$, stroke patients, patients with multiple-sclerosis, etc. [38, 39, 40, 41]. In the last few years, the use of VMR with visual and auditory feedback for improving balance control in subjects with PD in training sessions has become a promising research area $[42,43]$. The validation obtained using VMR systems confirms that the use of these techniques in therapeutic sessions is a good complement for reinforcing the traditional methods [44-47]. Recent studies using low-cost technology in the rehabilitation of patients with PD show good improvements in motor and non-motor skills, with an increase in ADL [48]. The use of Xbox Kinect in the training sessions produces improvements and stimulation of motor and cognitive tasks, providing greater stability in PD [49, 50]. In [51], the Nintendo Wii was used to test the short-term benefits in motor and non-motor therapies. The results showed positive enhancements in ADL in PD (using the UPDRS scale) in the intervention and follow-up assessments. The Nintendo ${ }^{\circledR}$ Wii Balance Board (WBB), together with customizable and motivating Virtual Environments, produces good results in balance and gait in patients with $P D$ $[52,53]$, however, there is no study that evaluates spatial postural control using VMR systems in this population.

\section{Objectives}

In this study, we tested and analyzed spatial postural control in patients with PD in the intervention period. For this purpose, we tested the participants using a novel and customizable low-cost tool, the Active Balance Rehabilitation (ABAR) system. To do this, we stored the pressure that the participants performed in each session on the WBB on the left, on the right and in the center in the sitting position. Rest and kinetic tremors and postural control are the most recognized symptoms in patients with PD. [54, $55,56]$.

\section{Methods}

\subsection{Participants}

We recruited patients with $\mathrm{PD}$ who use technical assistance (a cane, crutches, or a walker) or who do not use technical assistance for the experiment. Our study was approved by the Research Ethics Committee of Clínica de Aragón (CEIC), Zaragoza, Spain and was performed following the ethical standards of Declaration of Helsinki (DoH) [57]. Each participant signed a specific consent form before the experiment.

Ten patients with PD (4 males, 6 females;
$79.60 \pm 5.80$ years) performed the experiment to test spatial postural control in the sitting position, with a mean average related to the number of falls of .47 , a mean and a standard deviation score of calf circumference of 33.58(4.26), and a mean of a body-mass index of 27.14(4.26). The Hearing deficit/Non-Hearing deficit was $1 / 9$ and the Visual deficit/Non-Visual deficit was $7 / 3$.

Cognitive, functional, and emotional impairment clinical tests were calculated at the baseline evaluation: 1) the Mini-Mental state examination with a mean and a standard deviation score of (MEC-Lobo; 28.20(4.55)) [58]; 2) the Barthel index [59], with a mean and a standard deviation score of $76.29(17.87) ; 3$ ) Lawton's Philadelphia Geriatric Center Morale Scale [60] with a mean and a standard deviation score of (PGCMS; 08.86(3.72)); and 4) the Charlson comorbidity index [61] with a mean and a standard deviation score of $(\mathrm{CCl}$; $4.30(1.42))$.

Other parameter measures were: 1) number of drugs (8.34(3.53)), education, rural/urban area, therapist's time, and technical assistance in sessions.

The study was carried out using within the following criteria. The inclusion criteria were: 1) signed written informed consent before participating in the study; 2) age $\geq 18$ years and $\leq 92$; gait instability; 3) mild-moderate cognitive impairment (MEC-Lobo [58]) > 23; 4) comprehension of the instructions provided by the ABAR system; and 5) patients with PD with moderate visual/auditory injuries. The exclusion criteria were: 1) patients with PD with severe visual/auditory injuries; 2) traumatological injury that had not been solved before; and 3) refusal of the patient with PD. The details of the characteristics of the participants are shown in Table 1.

\subsection{ABAR system}

The ABAR system is composed of two levels of difficulty that are related to the weighttransferences that the participants perform in a specific session: the high level is composed of four Virtual Environments (VE) to carry out weight-transferences in the standing position; and the low level is composed of two VE to make weight-transferences in the sitting position. These VE were designed with the assistance of clinical specialist in the rehabilitation of patients with $\mathrm{PD}$, specifically therapists and geriatricians.

The hardware devices of the ABAR system are the following: 1) the Nintendo WBB which is an affordable, portable, and accessible device $(<\$ 100$ USD) that can be used to measure reaction forces when subjects are using it. Using this device it is possible to obtain similar outcomes to the commercial laboratory force platforms. It is composed of a platform with four uni-axial transducers located at the corners of the board, that capture the pressure that the subjects perform in the sitting position; 2) a lowcost bluetooth dongle to establish the 
Table 1 Detailed Characteristics of the Participants. This table shows the global information of the participants of the study: age, gender, disease duration, weight, height, and technical assistance (CA: Cane; C: Crutches; W: Walker).

\begin{tabular}{|c|c|c|c|c|c|c|c|c|c|}
\hline Subject ID & Gender & Age (years) & $\begin{array}{c}\text { Disease } \\
\text { duration } \\
\text { (years) }\end{array}$ & Weight & Height & $\begin{array}{l}\text { Technical } \\
\text { assistance }\end{array}$ & $\begin{array}{c}\text { Number of } \\
\text { drugs }\end{array}$ & Education & $\begin{array}{c}\text { Rural/urban } \\
\text { area }\end{array}$ \\
\hline 01 & $\mathrm{~F}$ & 71 & .4 & 62 & 1.62 & NO & 3 & Secondary & Urban \\
\hline 02 & $\mathrm{~F}$ & 79 & 2 & 85 & 1.7 & C & 12 & Primary & Urban \\
\hline 03 & M & 92 & 0.2 & 71 & 1.65 & C & 6 & Secondary & Urban \\
\hline 04 & M & 75 & 10 & 75 & 1.78 & NO & 10 & Primary & Urban \\
\hline 05 & $\mathrm{~F}$ & 82 & 5 & 60 & 1.51 & $C A$ & 7 & Primary & Urban \\
\hline 06 & $\mathrm{~F}$ & 82 & 10 & 64 & 1.53 & CA & 15 & Primary & Urban \\
\hline 07 & M & 76 & 15 & 53 & 1.62 & $C A$ & 10 & Primary & Urban \\
\hline 08 & $\mathrm{~F}$ & 78 & 1 & 82 & 1.56 & W & 7 & Primary & Urban \\
\hline 09 & $F$ & 77 & .6 & 65 & 1.53 & $C A$ & 5 & Primary & Urban \\
\hline 10 & M & 84 & 1 & 80 & 1.68 & CA & 8 & Higher & Urban \\
\hline Mean \pm STD & & $79.60(5.80)$ & $4.52(5.29)$ & $69.70(10.58)$ & $1.62(.09)$ & & $8.34(3.53)$ & & \\
\hline
\end{tabular}

communication with the WBB and the ABAR system; 3) a 2.1 speaker system to emit sound cues if they are necessary in the active sessions; and 4) a large 47" TV.

The weight-transferences that the ABAR system allows are medio/lateral and anterior/posterior weight-transferences in customizable sessions. To achieve these, we designed our system to be able to store the data related to the pressure from each session and to internally establish the limits of the weight distribution in medio/lateral and antero/posterior transferences.

In the virtual rehabilitation sessions, the therapist can select different options to customize the intervention phase. These parameters are the following: auditory feedback to reinforce the movements in the sitting position, volume, number of sessions to perform, and rest periods between sessions.

During the session, the therapist can select the number of minutes that the participants must perform. This time parameter indicates the number of seconds that the patient with PD has to reach the different targets that the VE shows.

Other parameters that the ABAR system offers are: the volume (increase/decrease in the level of volume), which is a great option for patients with moderate auditory injuries; the number of total training sessions in the intervention phase; and the rest period (in minutes). The details of the parameters of the training sessions are shown in Table 2.

The low level in our system is programmed to capture the level of pressure that the patient with PD performs in the training session. For this, we designed and programmed specific algorithms to store the types of pressure that the patients perform on the four uni-axial transducers of the WBB on-line.

\subsection{Protocol}

The study was performed in a small metropolitan hospital. The intervention sessions that the patients with PD carried out consisted of 15 rehabilitation sessions using the ABAR system in the sitting position, distributed in 2/3 sessions per week.

The rehabilitation sessions consisted of traditional and virtual rehabilitation, specifically 30 minutes using our system and 30 minutes in traditional rehabilitation, performing the same weight transferences in sitting position, with rest periods between VE of approximately five minutes. At the end of the first session, the patients with $\mathrm{PD}$ were invited to respond to the Suitability Evaluation Questionnaire (SEQ) [62]. The SEQ is based on the Short Feedback Questionnaire (SFQ) designed by Kizony et al. [63], and it tests the usability, security, and

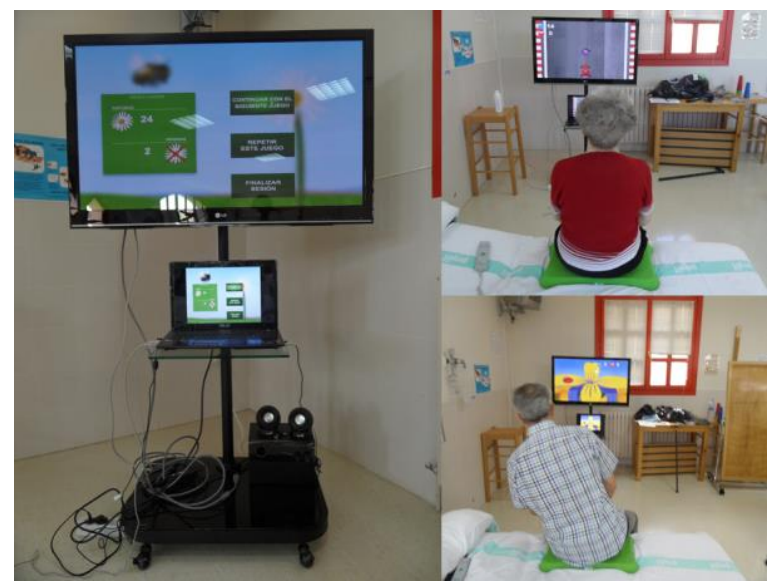

Figure 1 Patients with PD using the ABAR system acceptance of VMR systems. Figure 1 shows patients with $P D$ playing with the ABAR system.

The pressures that the ABAR system stored were based on five positions depending on the target that was shown: left, center, and right for medio/lateral weight transferences and left, center, right, up, and down for antero/posterior weight transferences.

The ABAR system stores the center of pressure (COP) of the patients twenty times per second. We use this measure for evaluating postural control.

The system induces the participants to maintain postural control in the different positions in order to achieve the goal. Our technological system stores the position of the COP of the patient every five hundredths of a second in every session.

When the participants maintained the position to achieve the targets, we selected the pressure that the participants performed when 
they maintained their body in these positions to be able to achieve the virtual target. Thanks to that, we could analyze their postural control. Afterwards, we analyzed the range of weighttransferences, measuring the variation of the COP.

This information was used to analyze and to compare the evolution of spatial postural control, the tremors in each session, and the distribution of the center of mass throughout the sessions. Thanks to this information, we were able to determine if the patients with PD increased their motor recovery in postural control.

\subsection{Data Analysis}

In this study, we analyzed the data by using SPSS 15.0. The analysis was carried out with a dependent sample t-test. Our results are normally distributed with a significance value $>.05$ using the Shapiro-Wilk test [64]. We selected this test with eleven grades of freedom because the number of participants was less than thirty subjects.

We confirmed that the $p$-value in the intervention period (initial and final evaluation) was greater than the type I error rate with a level of significance of .05 .

\section{Results}

The results obtained in patients with $P D$ in Baseline and Final Evaluation (intervention period) have not shown any statistical difference on the left, on the right, and in the central position.

The results show improvements in the intervention period. At the final evaluation the results were as follows: for left spatial postural control, the result ranges from 4.30 to 4.13 ; for central spatial postural control, the result ranges from 4.11 to 3.99 ; and for right spatial postural control, the result ranges from 4.49 to 4.12 . The mean final result shows a trend to improvement in spatial postural control (from .043 to .041). The results in Table 2 show the average and the standard deviation of the participants in baseline and final evaluation for left, right, and central postural control once we analyzed the pressures performed when the participants maintained their body in these positions.

Figure 2 shows the global average on the left, on the right, and in the center position regarding the postural instability that the participants had in each session of the experiment. The results for the suitability of the ABAR system for specific items were: enjoyment-Q1 (4.35(.9)), success (4.23(1.09)), clarity-Q6 (4.58(.73)), and helpfulness-Q11 $(3.88(.98))$.

\section{Discussion}

Adequate postural control is essential in daily life activities. Postural problems have serious consequences for patients. These problems not only limit their daily life, but they also increase

Table 2 Spatial postural control, average test scores: baseline (T0), final (T1).

\begin{tabular}{|c|c|c|c|}
\hline & Baseline Evaluation (T0) & Final Evaluation (T1) & p-value \\
\hline Left postural control & $4.30(.004)$ & $4.13(.005)$ & .393 \\
\hline Central postural control & $4.11(.005)$ & $3.99(.006)$ & .896 \\
\hline Right postural control & $4.49(.004)$ & $4.12(.005)$ & .142 \\
\hline Mean $\pm S T D$ & $4.30(.004)$ & $4.08(.005)$ & \\
\hline
\end{tabular}

some risks, like the risk of fall. Inadequate postural control and postural instability are major problems in PD patients. Postural control shares cognitive resources with other processes, and performance of postural tasks is often limited by other cognitive tasks. In this study, we propose the ABAR system, which has virtual environments follow a scheme similar to commercial video games. This system requires the patients to focus more on their cognitive processing in order to achieve the objectives of the games. Thus, we think that a scheduled rehabilitation program with ABAR could allow patients to maintain their postural control and even improve it.

ABAR offers tools to measure the postural control of patients; therefore, we can evaluate their performance through the sessions of the study.

Our proposal is in line with the growing scientific evidence that technology helps patients in their rehabilitation. Rehabilitation programs are currently changing, and they often integrate technology to increase the performance of the programs

The results demonstrate that patients maintain their postural control in the three positions. After fifteen sessions, there were no statistically significant differences in the performance of postural control in any of the three positions. However, the results do indicate a trend to improvement in all the positions. This trend to improvement is especially remarkable in the left/right positions, which are the most important positions to avoid problems like the risk of fall. We think that the main factor that

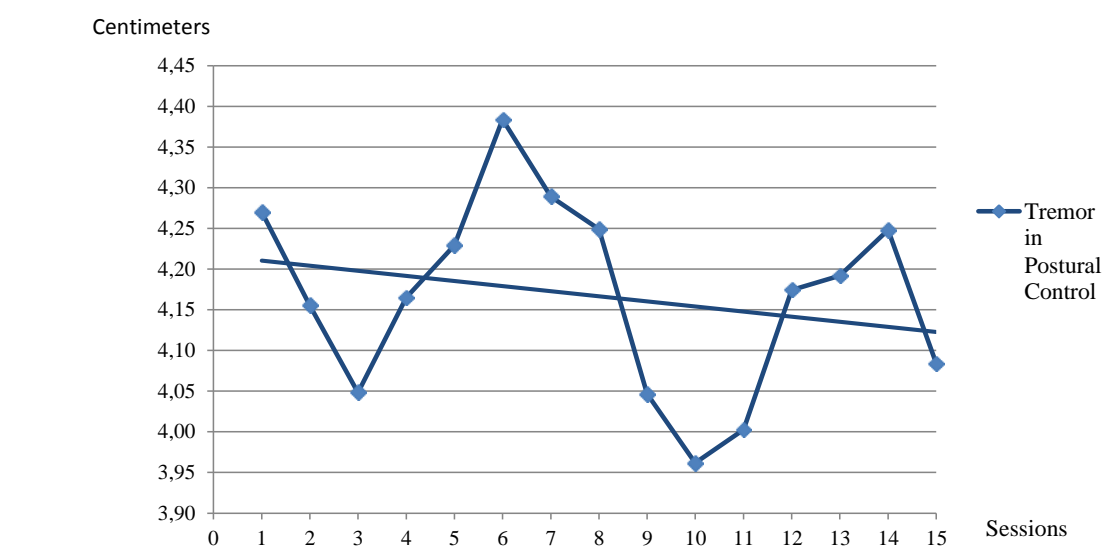

influences these results is that patients use more of their available cognitive processing to improve their postural control [65].

Since the participants using the ABAR system perform specific postural tasks, patients with PD, who have postural instability and cognitive dysfunction [66, 67], will need to increase their cognitive processing by performing more cognitive tasks. At the present time, we are designing a new protocol to test our experiment with more sessions. We consider that a greater number of sessions will produce statistically significant results.

The SEQ results indicated that patients with PD felt well, showing remarkable results in enjoyment, success, clarity, and helpfulness. We think that this is due to the fact that our system was designed specifically for patients with neurological disorders to perform weighttransferences.

To our knowledge, this is the first study that proposes a virtual rehabilitation system that supposes that patients with PD in virtual environments specifically require better cognitive processing to maintain or even improve postural control in the sitting position.

To promote cognitive processing, the system requires the continuous attention of patients in order to achieve the objectives of the games.

One of the main limitations of the study is the small sample size. Since the small sample limits the strength of the results, we are currently designing a new study with a larger sample. In this new study, we will also analyze the impact of the number of sessions evaluating how it affects the patients' performances.

\section{Figure 2 Mean and standard deviation of spatial postural control in the training sessions.}


Another limitation of the study is the lack of measures that determine the impact of the rehabilitation system in the ADL. Measures such as the number of falls would help to evaluate how the improvements are transferred to real life. Therefore, more measures are being considered for the new study in order to focus on measuring the ecological validity of the rehabilitation system.

\section{Conclusions}

The goal of this paper is to evaluate the evolution of postural control in PD patients using a virtual reality-based system that attempts to focus more specifically on their cognitive processing in order to maintain or improve their postural control.

Postural control is evaluated in three positions: left, central, and right. The central position is the position of the patient resting in the sitting position. The left/right positions are the bigger weight-transferences to the left/right that the patient can carry out in a controlled and stable way while seated. One of the advantages of ABAR is the capacity to determine the left/right position for each patient in each session through a previous calibration.

The ABAR system allows us to demonstrate that the use of VMR improves postural control in patients with PD because our system requires the continuous attention of patients, promoting cognitive processing.

The results of this study encourage us to continue along this line, especially considering the high prevalence of PD, (PD affects approximately $1 \%$ to $2 \%$ of the population over 65 years old [68]). In addition, we plan to extend the study to other patients with limited cognitive processing due to neurological impairments.

\section{Acknowledgements}

The authors would like to acknowledge all of the therapists of San José Hospital for their suggestions and their participation in this study. This contribution was partially funded by the Gobierno de Aragón, Departamento de Industria e Innovación, y Fondo Social Europeo "Construyendo Europa desde Aragón" and by the Programa Ibercaja-CAl de Estancias de Investigación.

\section{Author contributions}

S. Albiol-Pérez, J.A. Gil-Gómez, H. Gil-Gómez, and J.A. Lozano-Quilis contributed to the design of the ABAR system, the analysis of the results, and the draft of the paper. M.T. Muñoz-Tomás and R. Vial-Escolano contributed to the rehabilitation process and the clinical tests.

\section{References}

1. Schwartze M, Kotz SA. Regional Interplay for Temporal Processing in Parkinson's Disease: Possibilities and Challenges. Front Neurol. 2016 Jan 18:6:270.

2. Nussbaum RL, Ellis CE. Alzheimer's disease and
Parkinson's disease. N Engl J Med. 2003 Apr 3; 348(14):1356-64. Review. Erratum in: N Engl J Med. 2003 Jun 19; 348(25):2588.

3. Pringsheim T, Jette N, Frolkis A, Steeves TD. The prevalence of Parkinson's disease: a systematic review and meta-analysis. Mov Disord. 2014 Nov; 29(13):1583-90.

4. de Lau LM, Breteler MM. Epidemiology of Parkinson's disease. Lancet Neurol. 2006 Jun;5(6):525-35. Review.

5. King LA, Priest KC, Nutt J, Chen $Y$, Chen Z, Melnick M, Horak F. Comorbidity and functional mobility in persons with Parkinson disease. Arch Phys Med Rehabil. 2014 Nov;95(11):2152-7.

6. von Campenhausen $S$, Bornschein B, Wick R Bötzel K, Sampaio C, Poewe W, Oertel W, Siebert U, Berger K, Dodel R. Prevalence and incidence of Parkinson's disease in Europe. Eur Neuropsychopharmacol. 2005 Aug;15(4):473-90. Review.

7. Muangpaisan W, Hori H, Brayne C. Systematic review of the prevalence and incidence of Parkinson's disease in Asia. J Epidemiol. 2009;19(6):281-93. Epub 2009 Oct 3. Review.

8. Dorsey ER, Constantinescu R, Thompson JP Biglan KM, Holloway RG, Kieburtz K,Marshall FJ, Ravina BM, Schifitto G, Siderowf A, Tanner CM. Projected number of people with Parkinson's disease in the most populous nations, 2005 through 2030. Neurology. 2007 Jan 30;68(5):3846.

9. Chaudhuri KR, Odin P, Antonini A, MartinezMartin P. Parkinson's disease: the non-motor issues. Parkinsonism Relat Disord. 2011 Dec;17(10):717-23

10. Jankovic J. Parkinson's disease: clinical features and diagnosis. J Neurol Neurosurg Psychiatry. 2008 Apr;79(4):368-76

11. Weintraub D, Moberg PJ, Duda JE, Katz IR, Stern $M B$. Effect of psychiatric and other nonmotor symptoms on disability in Parkinson's disease. $J$ Am Geriatr Soc.2004 May:52(5):784-8.

12. Ondo WG, Dat Vuong K, Khan H, Atassi F, Kwak $\mathrm{C}$, Jankovic J. Daytime sleepiness and other sleep disorders in Parkinson's disease. Neurology. 2001 Oct 23;57(8):1392-6.

13. Shulman LM, Taback RL, Bean J, Weiner WJ. Comorbidity of the nonmotor symptoms of Parkinson's disease. Mov Disord. 2001 May;16(3):507-10.

14. Nolano M, Provitera V, Estraneo A, Selim MM Caporaso G, Stancanelli A,Saltalamacchia AM, Lanzillo B, Santoro L. Sensory deficit in Parkinson's disease: evidence of a cutaneous denervation. Brain. 2008 Jul:131(Pt 7):1903-11.

15. Micieli G, Tosi $P$, Marcheselli $S$, Cavallini $A$. Autonomic dysfunction in Parkinson's disease. Neurol Sci. 2003 May;24 Suppl 1:S32-4. Review.

16. Salat-Foix D, Suchowersky O. The management of gastrointestinal symptoms in Parkinson's disease. Expert Rev Neurother. 2012 Feb;12(2):239-48.

17. Nombela C, Bustillo PJ, Castell PF, Sanchez L, Medina V, Herrero MT. Cognitive Rehabilitation in Parkinson 's disease: Evidence from Neuroimaging. Frontiers in Neurology. 2011;2:82.

18. Poletti M, De Rosa A, Bonuccelli U. Affective symptoms and cognitive functions in Parkinson's disease. J Neurol Sci. 2012 Jun 15;317(1-2):97102.

19. Kashihara K. Weight loss in Parkinson's disease. J Neurol. 2006 Dec;253 Suppl 7:VII38-41. Review.

20. Fahn S. Description of Parkinson's disease as a clinical syndrome. Ann N Y Acad Sci. 2003 Jun;991:1-14. Review.

21. Crawford, P., Zimmerman, E.E., 2011 Differentiation and diagnosis of tremor. Am. Fam.
Physician. 2011; 83(6): 697-702.

22. Camara $C$, Isasi $P$, Warwick K, Ruiz V, Aziz T, Stein J, Baktein E. Resting tremor classification and detection in Parkinson's disease patients. Biomed. Signal Process. Control. 2015;16(0):8897.

23. Deuschl G, Bain P, Brin M. Consensus statement of the Movement Disorder Society on Tremor. Ad Hoc Scientific Committee. Mov Disord 1998; 13:2- 23.

24. Massano J, Bhatia KP. Clinical approach to Parkinson's disease: features, diagnosis, and principles of management. Cold Spring Harb Perspect Med. 2012 Jun;2(6):a008870.

25. Salarian A, Russmann $\mathrm{H}$, Wider $\mathrm{C}$, Burkhard PR, Vingerhoets FJ, Aminian K. Quantification of tremor and bradykinesia in Parkinson's disease using a novel ambulatory monitoring system. IEEE Trans Biomed Eng. 2007 Feb;54(2):31322.

26. Dai $H$, Zhang $P$, Lueth TC. Quantitative Assessment of Parkinsonian Tremor Based on an Inertial Measurement Unit. Sensors (Basel). 2015 Sep 29:15(10):25055-71.

27. Findley LJ, Gresty MA, Halmagyi GM. Tremor, the cogwheel phenomenon and clonus in Parkinson's disease. J Neurol Neurosurg Psychiatry. 1981 Jun;44(6):534-46.

28. Berardelli A, Rothwell JC, Thompson PD, Hallett M. Pathophysiology of bradykinesia in Parkinson's disease Brain Nov 2001, 124 (11) 2131-2146.

29. Bronnick K, Ehrt U, Emre M, De Deyn PP, Wesnes K, Tekin S, Aarsland D. Attentional deficits affect activities of daily living in dementiaassociated with Parkinson's disease. J Neurol Neurosurg Psychiatry. 2006 Oct;77(10):1136-42.

30. Horak FB. Postural orientation and equilibrium: what do we need to know about neural control of balance to prevent falls? Age Ageing. 2006 Sep;35 Suppl 2:ii7-ii11. Review.

31. Movement Disorder Society Task Force on Rating Scales for Parkinson's Disease. The Unified Parkinson's Disease Rating Scale (UPDRS): status and recommendations. Mov Disord. 2003 Jul;18(7):738-50. Review. Available online:

http://img.medscape.com/fullsize/701/816/58977 UPDRS.pdf

32. Goetz CG, Tilley BC, Shaftman SR, Stebbins GT, Fahn S, Martinez-Martin P,et al. Movement Disorder Society UPDRS Revision Task Force. Movement Disorder Society-sponsored revision of the Unified Parkinson's Disease Rating Scale (MDS-UPDRS): scale presentation and clinimetric testing results. Mov Disord. 2008:23(15):2129-70

33. Budzianowska A, Honczarenko K. Assessment of rest tremor in Parkinson's disease. Polish J. Neurol. Neurosurg. 2008:42:12-21.

34. Dibble LE, Hale TF, Marcus RL, Gerber JP, LaStayo PC. High intensity eccentric resistance training decreases bradykinesia and improves Quality Of Life in persons with Parkinson's disease: a preliminary study. Parkinsonism Relat Disord. 2009;15(10):752-7.

35. Dibble LE, Hale TF, Marcus RL, Droge J, Gerber JP, LaStayo PC. High-intensity resistance training amplifies muscle hypertrophy and functional gains in persons with Parkinson's disease. Mov Disord. 2006;21(9):1444-52.

36. McIntosh GC, Brown SH, Rice RR, Thaut MH. Rhythmic auditory-motor facilitation of gait patterns in patients with Parkinson's disease. Journal of Neurology, Neurosurgery, and Psychiatry. 1997:62(1):22-26.

37. Deane KH, Jones D, Playford ED, Ben-Shlomo 
Y, Clarke CE. Physiotherapy for patients with Parkinson's Disease: a comparison of techniques. Cochrane Database Syst Rev. 2001; (3):CD002817. Review.

38. Albiol-Pérez S., Lozano-Quilis J.A., Gil-Gómez H., Gil-Gómez J.A., Llorens R. 2012. Virtual rehabilitation system for people with Parkinson disease. 9th Intl Conf. Disability, Virtual Reality \& Associated Technologies, Laval, France.

39. dos Santos Mendes FA, Pompeu JE, Modenesi Lobo A, Guedes da Silva K, Oliveira Tde P Peterson Zomignani A, Pimentel Piemonte ME. Motor learning, retention and transfer after virtual-reality-based training in Parkinson's disease--effect of motor and cognitive demands of games: a longitudinal, controlled clinical study. Physiotherapy. 2012 Sep;98(3):217-23.

40. Saposnik G, Levin M; Outcome Research Canada (SORCan) Working Group.. Virtual reality in stroke rehabilitation: a meta-analysis and implications for clinicians. Stroke. 2011 May;42(5):1380-6.

41. Lozano-Quilis JA, Gil-Gómez H, Gil-Gómez JA Albiol-Pérez $S$, Palacios-Navarro $G$, Fardoun HM, Mashat AS. Virtual rehabilitation for multiple sclerosis using a kinect-based system: randomized controlled trial. JMIR Serious Games. 2014;2(2):e12

42. Badarny S, Aharon-Peretz J, Susel Z, Habib G, Baram Y. Virtual reality feedback cues for improvement of gait in patients with Parkinson's disease. Tremor Other Hyperkinet Mov (N Y). 2014 Apr 1; 4:225.

43. Ehgoetz Martens KA, Ellard CG, Almeida QJ. Does manipulating the speed of visual flow in virtual reality change distance estimation while walking in Parkinson's disease? Exp Brain Res. 2015 Mar;233(3):787-95

44. Albiol-Pérez S, Gil-Gómez JA, Llorens R, Alcañiz $M$, Font CC. The role of virtual motor rehabilitation: a quantitative analysis between acute and chronic patients with acquired brain injury. IEEE J Biomed Health Inform. 2014;18(1):391-8.

45. Albiol-Pérez $S$, Forcano-García $M$, MuñozTomás MT, Manzano-Fernández $P$, SolsonaHernández S, Mashat MA, Gil-Gómez JA. A novel virtual motor rehabilitation system for Guillain-Barré syndrome. Two single case studies. Methods Inf Med. 2015;54(2):127-34.

46. Gil-Gómez JA, Lloréns R, Alcañiz M, Colomer C. Effectiveness of a Wii balance board-based system (eBaViR) for balance rehabilitation: a pilot randomized clinical trial in patients with acquired brain injury. J Neuroeng Rehabil. 2011; $8: 30$.
47. Muñoz Tomás MT, Gil-Gómez JA, Gil-Gómez H Lozano-Quillis JA, Albiol-Pérez S, Forcano-García M. Suitability of virtual rehabilitation for the elderly: A study of a virtual rehabilitation system using the SEQ, European Geriatric Medicine 2013; 4(1):S109

48. Pompeu JE, Mendes FA, Silva KG, Lobo AM, Oliveira Tde P, Zomignani AP, Piemonte ME. Effect of Nintendo Wii ${ }^{\mathrm{TM}}$-based motor and cognitive training on activities of daily living in patients with Parkinson's disease: a randomized clinical trial. Physiotherapy. 2012 Sep;98(3):196204

49. Pompeu JE, Arduini LA, Botelho AR, Fonseca MB, Pompeu SM, Torriani-Pasin C, Deutsch JE. Feasibility, safety and outcomes of playing Kinect Adventures! ${ }^{\mathrm{TM}}$ for people with Parkinson's disease: a pilot study. Physiotherapy. 2014 Jun;100(2):162-8.

50. S. Summa, A. Basteris, E. Betti, and V. Sanguineti, "A feasibility study on using kinect for the rehabilitation in persons with Parkinson's disease,"Gait \& Posture, vol. 37, supplement 1, p. S15, 2013.

51. Herz NB, Mehta SH, Sethi KD, Jackson $P$, Hall $P$ Morgan JC. Nintendo Wii rehabilitation ("Wii-hab") provides benefits in Parkinson's disease. Parkinsonism Relat Disord. 2013 Nov;19(11):1039-42.

52. Holmes JD, Jenkins ME, Johnson AM, Hunt MA, Clark RA. Validity of the Nintendo Wiiß balance board for the assessment of standing balance in Parkinson's disease. Clin Rehabil. 2013:27(4):361-6.

53. Mhatre PV, Vilares I, Stibb SM, Albert MV, Pickering L, Marciniak CM, Kording K, Toledo S. Wii Fit balance board playing improves balance and gait in Parkinson disease. PM R. 2013 Sep;5(9):769-77.

54. Bächlin M, Plotnik M, Roggen D, Giladi N Hausdorff JM, Tröster G. A wearable system to assist walking of Parkinson $\mathrm{s}$ disease patients. Methods Inf Med. 2010;49(1):88-95.

55. Rigas G, Tzallas AT, Tsipouras MG, Bougia P Tripoliti EE, Baga D, Fotiadis DI, Tsouli SG, Konitsiotis S. Assessment of tremor activity in the Parkinson's disease using a set of wearable sensors. IEEE Trans Inf Technol Biomed. 2012 May;16(3):478-87.

56. Duval C. Rest and postural tremors in patients with Parkinson's disease. Brain Res Bull. 2006 Jun 15;70(1):44-8.

57. The World Medical Association Ethics Unit Declaration of Helsinki. http://www.wma.net/en/30publications/10policies/b $3 /$
58. Folstein MF, Folstein SE, McHugh PR. "Minimental state". A practical method for grading the cognitive state of patients for the clinician. J Psychiatr Res. 1975 Nov;12(3):189-98.

59. Collin C, Wade DT, Davies S, Horne V. The Barthel ADL Index: a reliability study. Int Disabil Stud 1988; 10(2):61-3.

60. Lawton MP. The Philadelphia Geriatric Center Morale Scale: a revision. J Gerontol. 1975 30(1):85-9.

61. Charlson ME, Pompei $\mathrm{P}$, Ales KL, MacKenzie CR. A new method of classifying prognostic comorbidity in longitudinal studies: development and validation. J Chronic Dis 1987; 40(5):373-83

62. Gil-Gómez JA, Manzano-Hernández $P$, AlbiolPérez S, Aula-Valero C, Gil-Gómez H, LozanoQuilis JA. SEQ: suitability evaluation questionnaire for virtual rehabilitation systems. Application in a virtual rehabilitation system for balance rehabilitation. In Proceedings of the 7th International Conference on Pervasive Computing Technologies for Healthcare (PervasiveHealth '13); 2013; ACM, New York, NY, USA, 335-338.

63. Kizony R, Katz N, Rand D, Weiss PL. A Short Feedback Questionnaire (SFQ) to enhance client-centered participation in virtual environments. 11th Annual Cyber Therapy Conference: Virtual Healing: Designing Reality, Gatineau, Canada. 2006.

64. Shapiro SS, Wilk MB. An analysis of variance test for normality (complete samples). Biometrika;1965;52(3-4): 591-611.

65. Horak FB. Postural orientation and equilibrium: what do we need to know about neural control of balance to prevent falls? Age Ageing. 2006 Sep;35 Suppl 2:ii7-ii11. Review.

66. Kim SD, Allen NE, Canning CG, Fung VS. Postural instability in patients with Parkinson's disease. Epidemiology, pathophysiology and management. CNS Drugs. 2013 Feb;27(2):97112

67. Robbins TW, Cools R. Cognitive deficits in Parkinson's disease: a cognitive neuroscience perspective. Mov Disord. 2014 Apr 15;29(5):597607

68. de Rijk MC, Tzourio C, Breteler MM, Dartigues JF, Amaducci L, Lopez-Pousa S,ManubensBertran JM, Alpérovitch A, Rocca WA Prevalence of parkinsonism and Parkinson's disease in Europe: the EUROPARKINSON Collaborative Study. European Community Concerted Action on the Epidemiology of Parkinson's disease. J Neurol Neurosurg Psychiatry. 1997 Jan;62(1):10-5. 